\title{
Steroid-induced insulin resistance and impaired glucose tolerance are both associated with a progressive decline of incretin effect in first-degree relatives of patients with type 2 diabetes
}

\author{
D. H. Jensen • K. Aaboe • J. E. Henriksen • A. Vølund • \\ J. J. Holst • S. Madsbad • T. Krarup
}

Received: 11 August 2011 / Accepted: 28 December 2011 / Published online: 29 January 2012

(C) Springer-Verlag 2012

\begin{abstract}
Aims/hypothesis The aim of this study was to evaluate the separate impact of insulin resistance and impaired glucose tolerance (IGT) on the incretin effect.

Methods Twenty-one healthy glucose-tolerant first-degree relatives of patients with type 2 diabetes underwent a $75 \mathrm{~g}$ OGTT, an isoglycaemic i.v. glucose test and a mixed meal to evaluate the incretin effect before and after treatment with dexamethasone to increase insulin resistance. Beta cell glucose sensitivity, beta cell index and fasting proinsulin were measured as indices of beta cell function.
\end{abstract}

D. H. Jensen $(\bowtie) \cdot$ T. Krarup

Department of Endocrinology, Bispebjerg University Hospital, Bispebjerg Bakke 23,

DK-2400 Copenhagen, Denmark

e-mail: David_hebbelstrup_Jensen@hotmail.com

K. Aaboe

Department of Endocrinology, Herlev University Hospital,

Herlev, Denmark

J. E. Henriksen

Department of Endocrinology, Odense University Hospital,

Odense, Denmark

\section{A. Vølund}

Department of Endocrinology,

Bispebjerg University Hospital Denmark,

Bispebjerg, Denmark

\section{J. J. Holst}

Department of Biomedical Sciences, The Panum Institute,

University of Copenhagen,

Copenhagen, Denmark

\section{S. Madsbad}

Department of Endocrinology, Hvidovre University Hospital, Hvidovre, Denmark
Results After dexamethasone, ten individuals had increased insulin resistance but normal glucose tolerance (NGT), while 11 individuals with an equal increase in insulin resistance developed IGT. In the NGT and IGT groups, the incretin effects were $71 \pm 3.2 \%$ and $67 \pm 4.6 \%(p=0.4)$ before treatment, but decreased significantly in both groups to $58 \pm 5.2 \%$ and $32 \pm 8.8 \%$ ( $p<0.05$ between groups) after treatment. Dexamethasone increased total glucagon-like peptide- 1 and glucose-dependent insulinotropic peptide responses to the OGTT. The impaired incretin effect in NGT was observed in the absence of reductions in beta cell glucose sensitivity and beta cell index during i.v. glucose, corrected for insulin resistance, but in parallel with increased proinsulin/C-peptide ratio. Conclusion/interpretation Insulin resistance and IGT, representing two stages in the path towards diabetes, are associated with differential reductions in the incretin effect seen before the development of IGT and overt type 2 diabetes. The reduction is unrelated to secretion of incretin hormones, but is related to insulin resistance and subtle beta cell defects, and is further aggravated on development of IGT.

Trial registration: ClinicalTrials.gov NCT00784745. Funding: This study was supported by a grant from the Novo Nordisk Foundation.

Keywords GIP. GLP-1 · Glucagon-like peptide-1 · Glucosedependent insulinotropic peptide · IGT, impaired glucose tolerance
Abbreviations
$\mathrm{D}_{\mathrm{I}} \quad$ Disposition index
FPG Fasting plasma glucose
GLP-1 Glucagon-like peptide-1
GIP Glucose-dependent insulinotropic peptide 
iAUC Incremental AUC

IGT Impaired glucose tolerance

ISR Insulin secretion rate

NGT Normal glucose tolerance

PG Plasma glucose

\section{Introduction}

'The incretin effect' is the phenomenon that oral glucose elicits a greater insulin response compared with glucose infused intravenously, giving identical plasma glucose profiles (isoglycaemia) [1]. It is mediated by two incretin hormones, glucagon-like peptide 1 (GLP-1) and glucosedependent insulinotropic polypeptide (GIP) [2-4].

The incretin effect is markedly reduced in type 2 diabetes $[5,6]$, and is diminished in individuals with impaired glucose tolerance (IGT) [7] and obesity [8]. The loss of the incretin effect is associated with a reduced insulinotropic effect of GLP-1 $[9,10]$ and an almost complete loss of latephase insulin secretion in response to GIP [10]. The incretin effect is also reduced in diabetes secondary to chronic pancreatitis [11], suggesting that the impairment is secondary to the development of diabetes [11] and raising the question of when the defect becomes apparent. Prediabetes is characterised by insulin resistance [12], and if secretion of insulin is insufficient to compensate for this, the result is IGT or frank diabetes [12].

We examined whether the incretin effect would be affected by induction of insulin resistance and/or development of IGT in healthy individuals. We used dexamethasone as an experimental tool to mimic the insulin resistance and glucose intolerance seen in prediabetes. In a previous study [13], shortterm dexamethasone resulted in increased insulin resistance in healthy relatives of individuals with type 2 diabetes; in addition, some participants developed glucose intolerance. By increasing insulin resistance to the same degree in all participants while inducing glucose intolerance in only some individuals, we aimed to isolate the individual impact of these two factors on the incretin effect. We examined first-degree relatives of individuals with type 2 diabetes and measured the incretin effect before and after dexamethasone [5, 14].

We also investigated whether a reduction in the incretin effect is associated with beta cell defects. The insulin response to i.v. glucose is impaired and proinsulin processing is defective in the early stages of development of type 2 diabetes $[15,16]$. Therefore, we evaluated beta cell function during the i.v. glucose test, and calculated the proinsulin/Cpeptide ratio in the fasting state as an index of beta cell dysfunction [16]. Normally, during changes in insulin sensitivity the beta cells respond with proportionate reciprocal changes in insulin secretion, thereby maintaining normal glucose tolerance (NGT) [17, 18]. Therefore, insulin secretion should be evaluated in relation to insulin resistance [19], to detect subtle beta cell defects [20]. Finally, all participants underwent a mixed meal before and after dexamethasone in order to examine beta cell function and incretin hormone secretion during physiological stimulation.

\section{Methods}

Participants Eleven men and ten women with at least one first-degree and one second-degree relative with type 2 diabetes underwent a $75 \mathrm{~g}$ OGTT to ensure NGT according to WHO criteria [21, 22]. After dexamethasone, the OGTT showed that one group retained NGT $(n=10)$, while the other developed IGT $(n=11)$. There were no significant differences in baseline characteristics between the groups (Table 1). All participants gave oral and written consent. The study was approved by Scientific Ethics Committee D of the Capital Region of Denmark (registration number H-D-2008-087), and followed the principles of the Helsinki Declaration II (registered with Clinicaltrials.gov, registration no. NCT00784745).

Experimental design Within 7 days of the start of dexamethasone, participants were studied on three different days with OGTT, i.v. glucose and a meal. The same three tests were performed on the three consecutive days immediately following 5 days of dexamethasone, $2 \mathrm{mg}$ twice daily. On days 1 and 2 after the 5 days of dexamethasone, $2 \mathrm{mg}$ dexamethasone was given in the afternoon. All participants were studied after an overnight $(10 \mathrm{~h})$ fast. On experimental days, with participants in the recumbent position, an i.v. catheter was inserted into an antebrachial vein and the arm was wrapped in a heating blanket in order to arterialise blood samples. [23]. The contralateral arm was cannulated for glucose infusion $(20 \%$ [wt/ vol.]). All participants ingested $75 \mathrm{~g}$ of water-free glucose dissolved in $300 \mathrm{ml}$ water. Blood samples were collected as indicated in Figs 1 and 2.

Table 1 Anthropometric data at baseline for patients who retained NGT or developed IGT after treatment with dexamethasone

\begin{tabular}{lll}
\hline Characteristic & NGT & IGT \\
\hline$n$ (women/men) & $4 / 6$ & $5 / 6$ \\
Age (years) & $27 \pm 2.4$ & $29 \pm 2.4$ \\
BMI $\left(\mathrm{kg} / \mathrm{m}^{2}\right)$ & $23 \pm 1.0$ & $25 \pm 0.9$ \\
$\mathrm{FPG}(\mathrm{mmol} / \mathrm{l})$ & $5.0 \pm 0.07$ & $5.1 \pm 0.12$ \\
$\mathrm{PG}_{120}(\mathrm{mmol} / \mathrm{l})$ & $6.2 \pm 0.20$ & $6.4 \pm 0.22$ \\
Matsuda index & $8.4 \pm 1.2$ & $6.2 \pm 0.90$ \\
\hline
\end{tabular}

There were no significant differences between groups

Matsuda index was calculated from the OGTT

$\mathrm{PG}_{120}$, plasma glucose at $120 \mathrm{~min}$ during the $75 \mathrm{~g}$ OGTT 

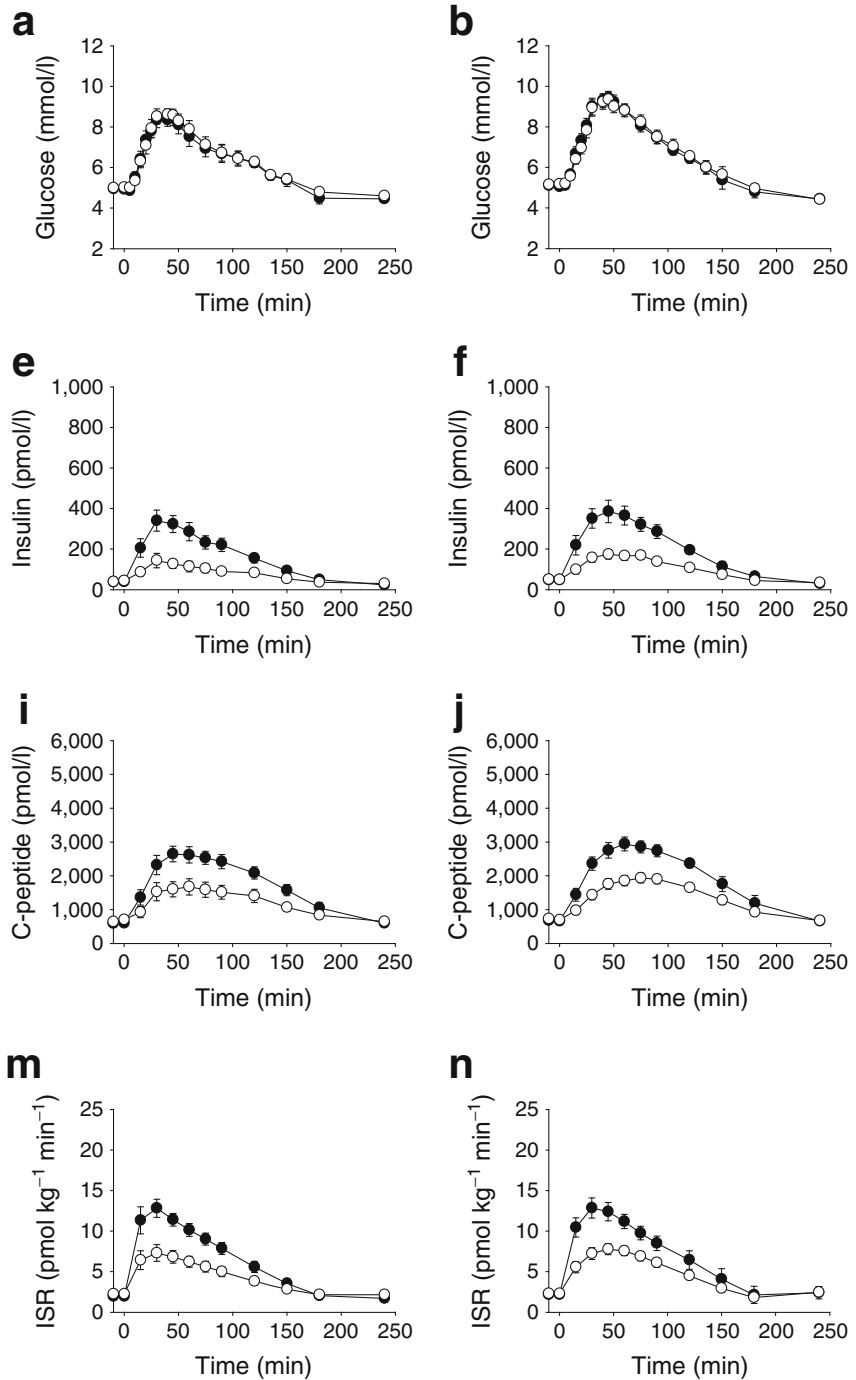

Fig. 1 Results during the $75 \mathrm{~g}$ OGTT and the isoglycaemic i.v. glucose infusion. a-d PG: (a) NGT before dexamethasone; (b) IGT before dexamethasone; (c) NGT after dexamethasone; and (d) IGT after dexamethasone. e-h Plasma insulin: (e) NGT before dexamethasone; (f) IGT before dexamethasone; (g) NGT after dexamethasone; and (h) IGT after dexamethasone. i-l Plasma C-peptide: (i) NGT before

The plasma glucose (PG) curves from the OGTT were copied by i.v. infusion of $20 \%$ glucose, guided by frequent measurements of PG. On a separate day, a mixed meal (200 $\mathrm{ml}$ low-fat milk, $50 \mathrm{~g}$ white bread, $50 \mathrm{~g}$ rye bread, $10 \mathrm{~g}$ butter, $40 \mathrm{~g}$ cheese and $20 \mathrm{~g}$ jam [34\% fat, $47 \%$ carbohydrate, $19 \%$ protein; a total of $2,370 \mathrm{~kJ}]$ ) was ingested within $15 \mathrm{~min}$. The sequence of OGTT and test meal was randomised. Blood samples were drawn as indicated in Figs 3 and 4.

Blood samples PG was measured at the bedside from blood sampled in fluoride-containing tubes, and immediately centrifuged for $1 \mathrm{~min}$ at 7,400 $\mathrm{g}$ at room temperature. Blood for the measurement of GLP-1, GIP and glucagon was
C
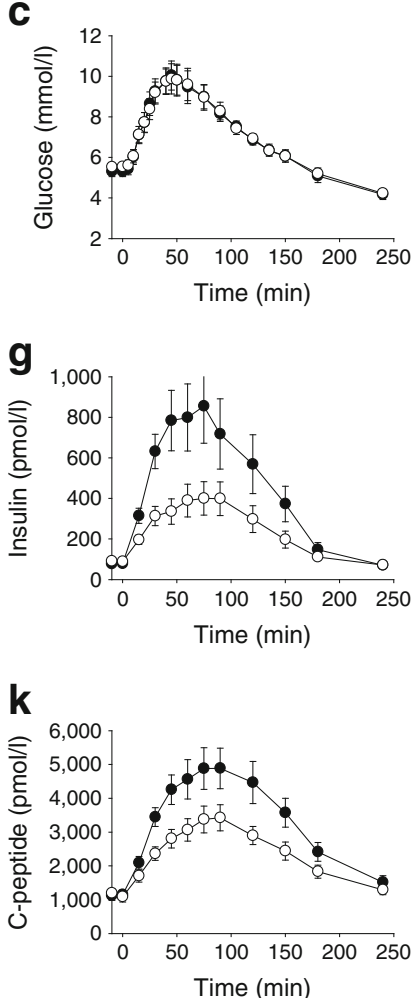

o

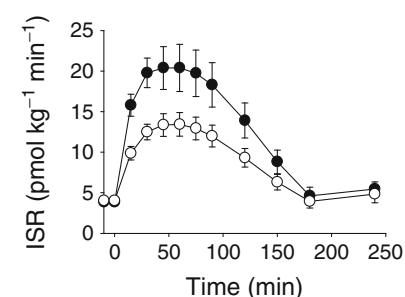

d
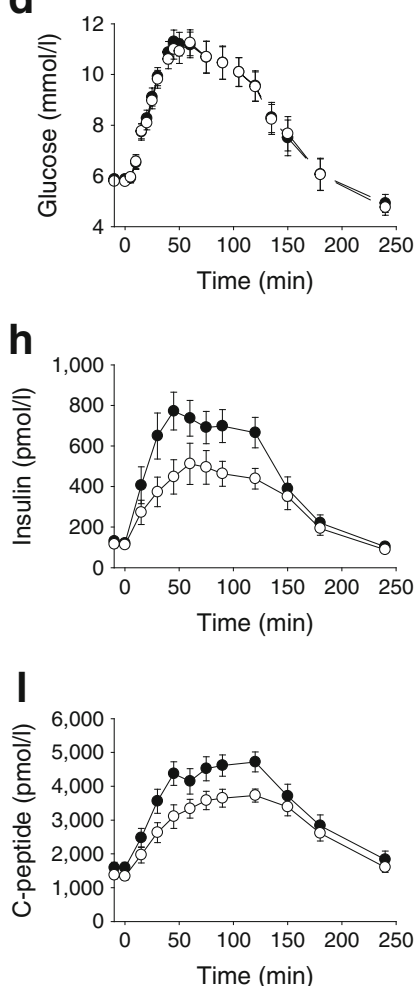

p

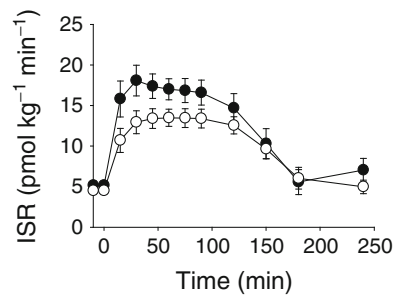

dexamethasone; (j) IGT before dexamethasone; (k) NGT after dexamethasone; and (l) IGT after dexamethasone. $\mathbf{m}-\mathbf{p}$ ISR: (m) NGT before dexamethasone; (n) IGT before dexamethasone; (o) NGT after dexamethasone; and (p) IGT after dexamethasone. Black circles, during the 75 g OGTT; white circles, during isoglycaemic i.v. glucose infusion

distributed into chilled tubes containing EDTA, which were immediately placed on ice and subsequently centrifuged at $4^{\circ} \mathrm{C}$ for $15 \mathrm{~min}$ at $1,200 \mathrm{~g}$. Plasma was stored at $-20^{\circ} \mathrm{C}$, with the exception of plasma for insulin and C-peptide, which was stored at $-80^{\circ} \mathrm{C}$.

Analyses PG concentrations were measured by the glucose oxidase method, using a glucose analyser (2300 Stat Plus analyser; YSI, Yellow Springs, OH, USA). Plasma samples were assayed for total GLP-1 as previously described [24], using a radioimmunoassay with antiserum specific for the C-terminal of the GLP-1 molecule (antiserum 89390, produced in house), which therefore reacts equally with intact GLP-1 and the primary (N-terminally truncated) metabolite. 

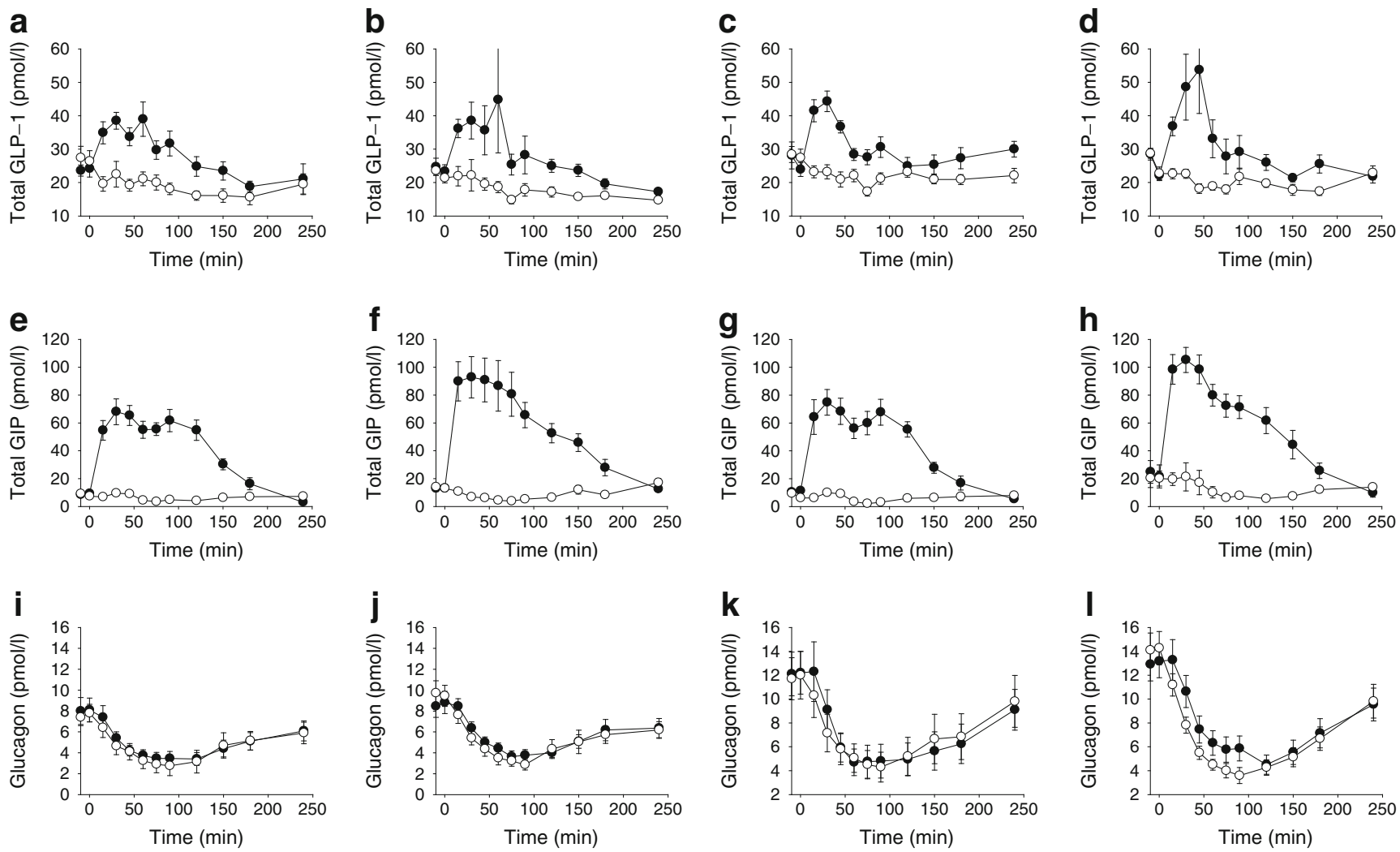

Fig. 2 Results during the $75 \mathrm{~g}$ OGTT and the isoglycaemic i.v. glucose infusion. a-d Total GLP-1: (a) NGT before dexamethasone; (b) IGT before dexamethasone; (c) NGT after dexamethasone; and (d) IGT after dexamethasone. e-h Total GIP: (e) NGT before dexamethasone; (f) IGT before dexamethasone; (g) NGT after dexamethasone; and (h)

Total GIP was measured using the C-terminally directed antiserum R65, produced in house [25, 26], which reacts fully with intact GIP and the N-terminally truncated metabolite. The glucagon assay is directed against the C-terminal (antibody 4305, produced in house) and measures glucagon of mainly pancreatic origin [27-29]. Plasma insulin and Cpeptide were measured using the Autodelphia automatic fluoroimmunoassay (Wallac, Turku, Finland). Proinsulin was analysed using a two-site enzyme-linked immunoadsorbent assay based on two monoclonal antibodies [30].

Calculations and statistical analysis All results are expressed as mean $\pm \mathrm{SEM}$. AUCs were calculated using the trapezoidal rule and are presented as total or incremental values (baseline values subtracted), as indicated. Incretin effects were calculated by the following formula: $100 \times($ incremental [i] AUC) during OGTT-iAUC during i.v. glucose infusion)/ iAUC during OGTT. Insulin secretion rate (ISR) was calculated by deconvolution of plasma C-peptide and application of population-based variables for C-peptide kinetics [31]. ISR is expressed as pmol kg${ }^{-1} \mathrm{~min}^{-1}$. Insulin resistance was estimated by the Matsuda index, which is calculated using only values obtained from the OGTT [32].
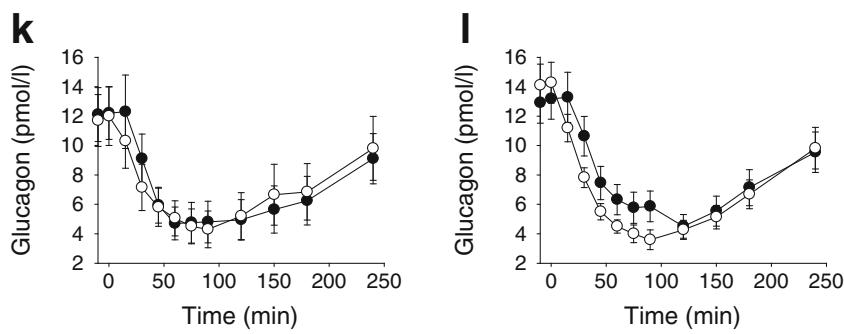

IGT after dexamethasone. i-l Glucagon: (i) NGT before dexamethasone; (j) IGT before dexamethasone; (k) NGT after dexamethasone; and (l) IGT after dexamethasone. Black circles, during the $75 \mathrm{~g}$ OGTT; white circles, during isoglycaemic i.v. glucose infusion

We estimated beta cell glucose sensitivity based on the relationship between ISR and glucose levels during the three tests. The calculated ISR was plotted against PG to establish the dose-response relationship (beta cell glucose sensitivity) for each individual on each experimental day, and the slopes of these linear relations during the upstroke phase of the insulin response were expressed as pmol kg${ }^{-1} \min ^{-1}(\mathrm{mmol} / \mathrm{l})^{-1}$ [9]. We used this variable to estimate the potentiating effect of the incretin hormones, i.e. a measure of the dynamic 'incretin effect', by calculating the ratio of beta cell glucose sensitivity during the OGTT to the i.v. glucose infusion. In addition, we calculated the 'beta cell index', i.e. the ratio of $\mathrm{iAUC}_{\mathrm{ISR}}$ to $\mathrm{iAUC}_{\mathrm{Glucose}}$ during the $240 \mathrm{~min}\left(\mathrm{iAUC}_{\mathrm{ISR}} / \mathrm{iAUC}_{\mathrm{Glucose}}\right)$. Beta cell function was related to insulin resistance by calculation of the disposition index $\left(\mathrm{D}_{\mathrm{I}[\mathrm{Glucose}}\right.$ sensitivity] $)$ i.e. beta cell glucose sensitivity $\times$ Matsuda index and the disposition index $\left(\mathrm{D}_{\mathrm{I}[\text { Beta cell index }]}\right)$, i.e. $\left(\mathrm{iAUC}\right.$ insulin $\left./ \mathrm{iAUC}_{\text {glucose }}\right) \times$ Matsuda index), assuming the existence of an inverse hyperbolic relationship between insulin secretion and action. To evaluate this, we performed weighted least-squares linear regression analysis [33] with log beta cell glucose sensitivity as the dependent and $\log$ Matsuda index as the independent variable, and also between $\log \mathrm{iAUC}_{\mathrm{ISR}} / \mathrm{iAUC}_{\mathrm{Glucose}}$ 
a
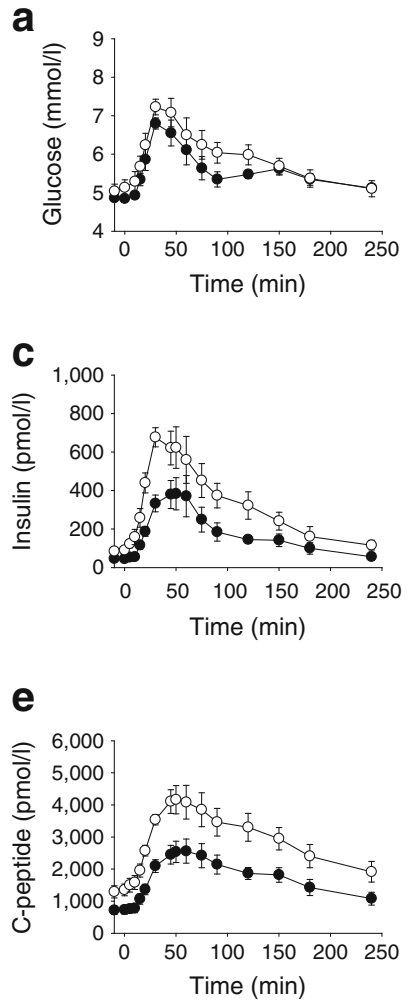

g

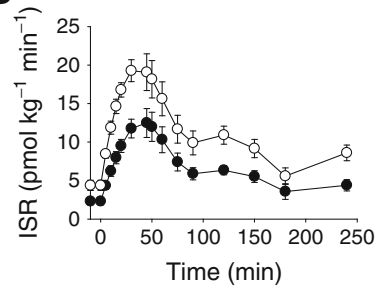

b

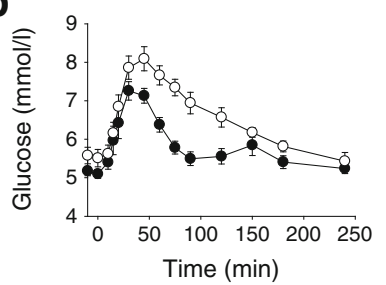

d

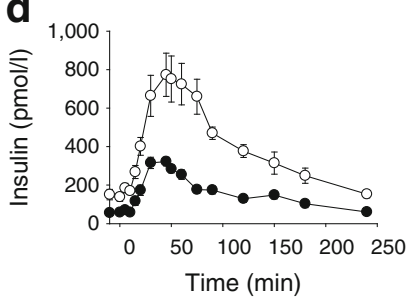

f

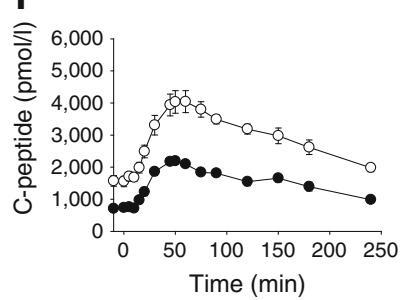

h

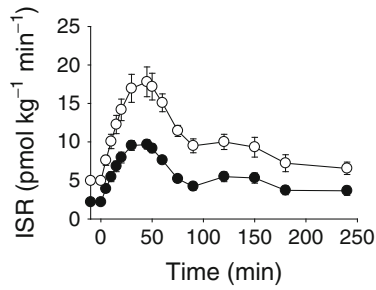

Fig. 3 Results before and after treatment with dexamethasone during the mixed meal for: (a, b) PG; (c, d) plasma insulin; (e, f) plasma Cpeptide; and (g, h) ISR. Results are shown for the NGT (a, c, e, g) and IGT (b, d, f, h) groups. Black circles, before treatment; white circles, after treatment

and $\log$ Matsuda index for all the participants during i.v. glucose before and after dexamethasone. Ideally, the slope of this relationship should be -1.0 . For $\mathrm{D}_{\mathrm{I}(\mathrm{Glucose} \text { sensitivity) }}$ the slope of the regression line before dexamethasone was $-0.45\left(95 \%\right.$ CI $\left.-0.54,-0.044 ; r_{2}=0.24, p<0.05\right)$, and for $\mathrm{D}_{\mathrm{I}(\text { Beta cell index })}-0.72(95 \% \mathrm{CI}-1.51,-0.47$; $\left.r^{2}=0.44, p<0.05\right)$ justifying the calculation of the two $\mathrm{D}_{\mathrm{I}}$ values. After dexamethasone, the slope of the line for $\mathrm{D}_{\mathrm{I}(\mathrm{Glucose} \text { sensitivity) }}$ was $-0.48(95 \% \mathrm{CI}-0.64,-0.14$; $\left.r^{2}=0.30, p<0.05\right)$ and for $\mathrm{D}_{\mathrm{I}(\text { Beta cell index })}-0.61(95 \%$ CI $-0.78,-0.25 ; r^{2}=0.40, p<0.05$ ).

Wilcoxon's test was used for within-group differences and Mann-Whitney $U$ test for between-group differences because of the non-normal distribution of the data. Our power calculation before undertaking the study (power of
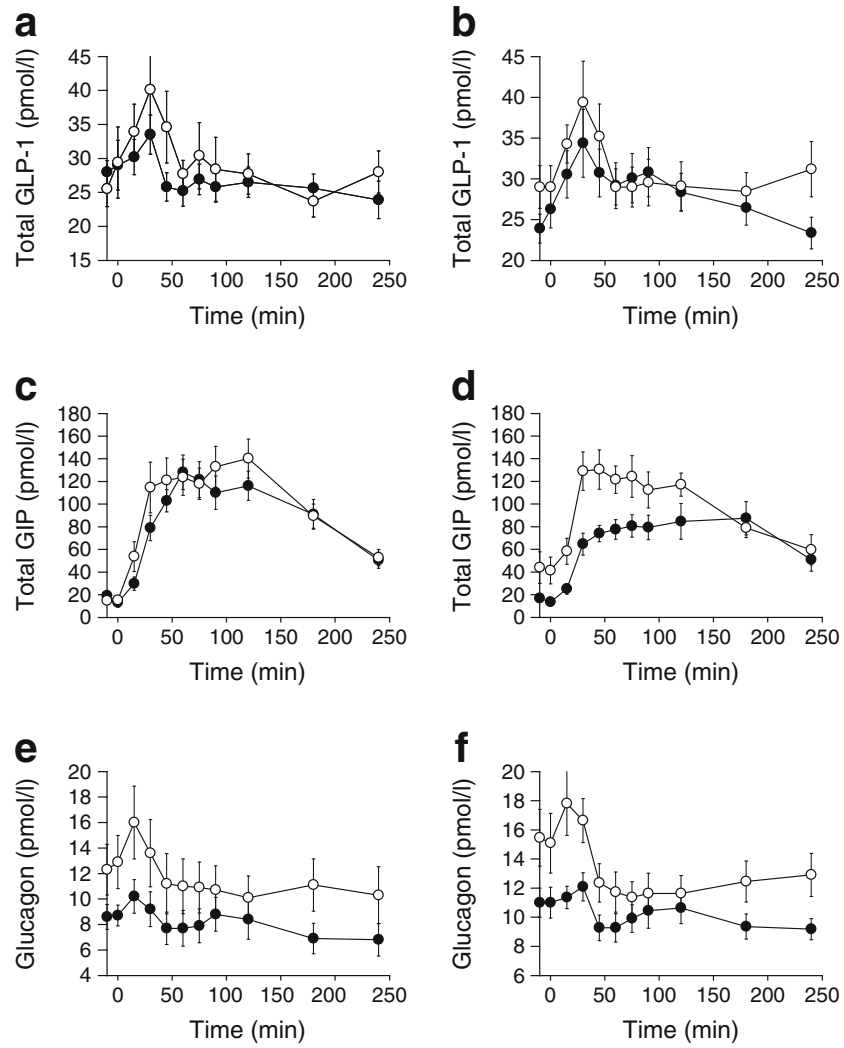

Fig. 4 Results before and after treatment with dexamethasone during the mixed meal for: (a, b) total GLP-1; (c, d) total GIP; and (e, f) glucagon. Results are shown for the NGT $(\mathbf{a}, \mathbf{c}, \mathbf{e}$,$) and IGT (\mathbf{b}, \mathbf{d}, \mathbf{f})$ groups. Black circles, before treatment; white circles, after treatment

$80 \%$ ) indicated that a $25 \%$ change in incretin effect required eight participants to achieve statistical significance at the $5 \%$ level (two-sided paired $t$ test). However, because of the nonnormal distribution, the less powerful Wilcoxon test had to be used, but the approximate $20 \%$ decrease in incretin effect in the NGT group reached statistical significance. Linear regression analysis was performed using standard methods. A $p$ value $<0.05$ was considered statistically significant.

\section{Results}

Glucose Fasting PG (FPG) concentrations were similar on all three experimental days before and after dexamethasone in the two groups. Dexamethasone increased FPG in both the NGT $(5.0 \pm 0.06$ vs $5.3 \pm 0.12 \mathrm{mmol} / 1, p<0.05)$ and IGT $(5.1 \pm 0.07$ vs $5.7 \pm 0.10 \mathrm{mmol} / \mathrm{l})$ groups $(p<0.05$ for the increase in FPG in both groups); $p<0.05$ for the difference between the two groups after treatment.

The glucose curves on the OGTT and i.v. glucose infusion days were similar (isoglycaemia) before and after dexamethasone (Fig. 1a-d). AUC during the OGTT and i.v. glucose infusion increased significantly 
in both groups after treatment $(p<0.05)$, and during the mixed meal in IGT (Table 2). There were no significant differences between groups before dexamethasone during any of the tests. However, after dexamethasone, the AUC increased significantly in the IGT compared with the NGT group in all tests $(p<0.05)$. The iAUC increased significantly in both groups during OGTT and the i.v. glucose infusion. There were no differences in iAUC between the groups for any test. That a difference was found between groups using total AUC and not iAUC is related to the differences in FPG values.
The total amounts of glucose infused in NGT vs IGT were $28.1 \pm 2.2$ vs $36.0 \pm 2.2 \mathrm{~g}(p<0.05)$ before and $44.2 \pm 3.0$ vs $64.1 \pm 3.9 \mathrm{~g}$ after $(p<0.05)$ dexamethasone.

Total GLP-1 Plasma GLP-1 levels are presented in Figs 2 a$\mathrm{d}$ and $4 \mathrm{a}-\mathrm{d}$. There were no baseline differences before (NGT $30 \pm 3.8$ vs IGT $27 \pm 2.6 \mathrm{pmol} / \mathrm{l}$ ) or after (NGT $27 \pm 1.7$ vs IGT $29 \pm 1.0$ pmol/l) dexamethasone. There were no significant differences between groups regarding AUCs of any of the tests before or after treatment with dexamethasone. The AUCs increased numerically in both groups during all three
Table 2 AUC and iAUC values for glucose, GLP-1, GIP and glucagon in response to an oral glucose load (75 g), the isoglycaemic i.v. glucose infusion and a mixed meal before and after dexamethasone
The AUC and iAUC values represent the total and incremental areas during the $240 \mathrm{~min}$ tests

*Significant difference between groups $(p<0.05)$

${ }^{\dagger}$ Significant differences between OGTT and i.v. glucose infusion within groups $(p<0.05)$

${ }^{\ddagger}$ Significant differences within groups before compared with after treatment $(p<0.05)$

\begin{tabular}{|c|c|c|c|c|}
\hline \multirow[t]{2}{*}{ Variable } & \multicolumn{2}{|l|}{ Before } & \multicolumn{2}{|l|}{ After } \\
\hline & NGT group & IGT group & NGT group & IGT group \\
\hline$n$ (women/men) & $4 / 6$ & $5 / 6$ & $4 / 6$ & $5 / 6$ \\
\hline \multicolumn{5}{|l|}{ AUC } \\
\hline \multicolumn{5}{|l|}{ Glucose $(\mathrm{mol} / 1 \times \min )$} \\
\hline OGTT & $1.4 \pm 0.05$ & $1.5 \pm 0.03$ & $1.6 \pm 0.05^{*}$, & $2.0 \pm 0.1^{*}$, \\
\hline i.v. glucose infusion & $1.5 \pm 0.04$ & $1.5 \pm 0.03$ & $1.6 \pm 0.05^{*}$, & $2.0 \pm 0.1^{*}$, \\
\hline Mixed meal & $1.3 \pm 0.03$ & $1.4 \pm 0.02$ & $1.4 \pm 0.05^{*}$ & $1.6 \pm 0.04^{*}$, \\
\hline \multicolumn{5}{|c|}{ Total GLP-1 (nmol/1× min) } \\
\hline OGTT & $6.5 \pm 0.5^{\dagger}$ & $6.4 \pm 0.6^{\dagger}$ & $7.2 \pm 0.5^{\dagger, \star}$ & $7.1 \pm 0.6^{\dagger, 末}$ \\
\hline i.v. glucose infusion & $4.4 \pm 0.3$ & $4.2 \pm 0.3$ & $5.2 \pm 0.3$ & $4.8 \pm 0.2^{\ddagger}$ \\
\hline Mixed meal & $6.4 \pm 0.3$ & $6.7 \pm 0.5$ & $6.9 \pm 0.8$ & $7.3 \pm 0.64$ \\
\hline \multicolumn{5}{|l|}{ Total GIP $(\mathrm{nmol} / 1 \times \min )$} \\
\hline OGTT & $9.3 \pm 0.7^{\dagger}$ & $9.9 \pm 1.0^{\dagger}$ & $12.7 \pm 1.5^{\dagger, t}$ & $13.2 \pm 1.3^{\dagger, t}$ \\
\hline i.v. glucose infusion & $1.5 \pm 0.2$ & $1.5 \pm 0.2$ & $2.1 \pm 0.3^{\ddagger}$ & $2.8 \pm 0.6^{\ddagger}$ \\
\hline Mixed meal & $21.7 \pm 1.8$ & $17.3 \pm 2.1$ & $24.3 \pm 2.3^{*}$ & $23.1 \pm 1.8^{\ddagger}$ \\
\hline \multicolumn{5}{|l|}{ Glucagon (nmol/1× min) } \\
\hline OGTT & $1.1 \pm 0.2$ & $1.2 \pm 0.1$ & $1.6 \pm 0.4$ & $1.8 \pm 0.2^{*}$ \\
\hline i.v. glucose infusion & $1.1 \pm 0.2$ & $1.2 \pm 0.2$ & $1.6 \pm 0.4^{\ddagger}$ & $1.6 \pm 0.2^{*}$ \\
\hline Mixed meal & $1.9 \pm 0.3$ & $2.4 \pm 0.2$ & $2.7 \pm 0.5^{\ddagger}$ & $3.1 \pm 0.3^{*}$ \\
\hline \multicolumn{5}{|l|}{ iAUC } \\
\hline \multicolumn{5}{|l|}{ Glucose $(\mathrm{mol} / 1 \times \min )$} \\
\hline OGTT & $0.24 \pm 0.04$ & $0.31 \pm 0.05$ & $0.36 \pm 0.04^{*}$ & $0.56 \pm 0.8^{* \star \sharp}$ \\
\hline i.v. glucose infusion & $0.26 \pm 0.04$ & $0.31 \pm 0.05$ & $0.32 \pm 0.04^{*}$, & $0.57 \pm 0.09^{*}$, \\
\hline Mixed meal & $0.18 \pm 0.03$ & $0.16 \pm 0.02$ & $0.19 \pm 0.02$ & $0.23 \pm 0.04$ \\
\hline \multicolumn{5}{|c|}{ Total GLP-1 (nmol/1× min) } \\
\hline OGTT & $0.72 \pm 0.4^{\dagger}$ & $0.62 \pm 0.71^{\dagger}$ & $1.0 \pm 0.6^{\dagger}$ & $1.0 \pm 0.7^{\dagger}$ \\
\hline i.v. glucose infusion & $-2.1 \pm 0.5$ & $-1.2 \pm 0.3$ & $-1.5 \pm 0.3$ & $-1.4 \pm 0.5$ \\
\hline Mixed meal & $-17 \pm 2.5$ & $-17 \pm 1.5$ & $0.33 \pm 0.4$ & $-0.27 \pm 0.6$ \\
\hline \multicolumn{5}{|l|}{ Total GIP $(\mathrm{nmol} / 1 \times \min )$} \\
\hline OGTT & $7.2 \pm 0.8^{\dagger}$ & $7.3 \pm 1.0^{\dagger}$ & $9.6 \pm 1.1^{\dagger, t}$ & $7.7 \pm 1.9^{\dagger}$ \\
\hline i.v. glucose infusion & $-0.47 \pm 0.2$ & $-0.36 \pm 0.2$ & $-1.1 \pm 0.4$ & $-2.1 \pm 0.9$ \\
\hline Mixed meal & $18 \pm 2.1$ & $14 \pm 2.1$ & $21 \pm 2.6^{\ddagger}$ & $13 \pm 2.9$ \\
\hline \multicolumn{5}{|l|}{ Glucagon $(\mathrm{nmol} / 1 \times \min )$} \\
\hline OGTT & $-0.8 \pm 0.2$ & $-0.9 \pm 0.1$ & $-1.3 \pm 0.2^{\ddagger}$ & $-1.3 \pm 0.2^{\dagger+\star}$ \\
\hline i.v. glucose infusion & $-0.7 \pm 0.1$ & $-1.2 \pm 0.1$ & $-1.2 \pm 0.3^{* \star}$ & $-1.8 \pm 0.2^{* \dagger}$ \\
\hline Mixed meal & $-0.2 \pm 0.2$ & $-0.2 \pm 0.2$ & $-0.3 \pm 0.1$ & $-0.6 \pm 0.2$ \\
\hline
\end{tabular}


tests after dexamethasone, and significantly in IGT during OGTT and the i.v. glucose infusion and during OGTT in NGT $(p<0.05$; Table 2$)$. The iAUC did not change significantly in either group in any test after dexamethasone, and there were no significant differences between groups in any tests before or after dexamethasone. The differences observed between incremental and total values are related to the increase seen in fasting GLP-1.

Total GIP There were no baseline differences in fasting GIP between the three experimental days in the two groups, either before or after dexamethasone (Figs $2 \mathrm{e}-\mathrm{h}$ and $4 \mathrm{e}-\mathrm{h}$ ). Within each group, there was a highly significant increase in fasting values from $9.1 \pm 1.0$ to $14 \pm 1.2 \mathrm{pmol} / 1(p<0.001)$ in the NGT group and from $11 \pm 1.1$ to $29 \pm 5.5 \mathrm{pmol} / 1$ after dexamethasone $(p<0.001)$ in the IGT group.

There were no significant differences in total AUC or iAUC between groups in any of the tests (Table 2). The AUCs increased significantly in both groups in all three tests after dexamethasone whereas iAUCs only increased significantly in the NGT group during the OGTT and the mixed meal.

Insulin, C-peptide and ISR Fasting insulin, C-peptide and ISR values did not differ between groups on the three experimental days before dexamethasone (Figs 1e-h and $\mathrm{i}-1$ and $3 \mathrm{e}-\mathrm{h}$ and $\mathrm{i}-\mathrm{j})$. All three variables increased in both groups after treatment $(p<0.05)$, but to a greater extent in the IGT group compared with the NGT group $(p<0.05)$.

The iAUC for insulin, C-peptide and ISR were greater in both groups during OGTT compared with i.v. glucose infusion both before and after dexamethasone $(p<0.05$; Table 3$)$. The iAUCs increased two- to threefold after dexamethasone in both groups during oral and i.v. glucose $(p<0.05)$, but did not differ significantly between the two groups (Table 3 ). During the mixed meal, the insulin, C-peptide and ISR responses increased significantly in both groups after dexamethasone, but the responses were similar in the two groups both before and after dexamethasone (Table 3).

Incretin effects The incretin effect, calculated from insulin iAUC, was $71 \pm 3.2 \%$ and $67 \pm 4.6 \%$ before $(p=0.4)$ and $58 \pm$ $5.2 \%$ and $32 \pm 8.8 \%$ after treatment $(p<0.05)$, in the NGT and IGT groups, respectively (Table 3 ). In both groups, the incretin effect was reduced after dexamethasone $(p<0.05)$. The incretin effect, calculated from C-peptide or ISR, was smaller compared with that calculated from insulin, but with concordant changes (Table 3). The dynamic 'incretin effect' estimated by beta cell glucose sensitivity during oral and i.v. glucose was 2.6 \pm 0.33 (NGT) and 2.1 \pm 0.31 (IGT) $(p=0.3$ ) before, and decreased to $1.6 \pm 0.22$ and $1.4 \pm 0.10(p=0.057)$, respectively, after dexamethasone. The decrease was significant in both groups $(p<0.05)$.
Matsuda index The Matsuda index before treatment was $8.4 \pm 1.2(\mathrm{NGT})$ and $6.2 \pm 0.90$ (IGT) $(p=0.12)$. After dexamethasone, the Matsuda index decreased significantly in both groups $(p<0.05)$ to $3.6 \pm 0.62$ and $2.6 \pm 0.19$, respectively $(p=0.14)$. The decrease in Matsuda index did not differ between groups $(p=0.3)$

Proinsulin/C-peptide ratio The proinsulin/C-peptide ratios were similar at baseline, but increased after dexamethasone from $1.4 \pm 0.14$ to $2.3 \pm 0.30(p<0.05)$ in the NGT group and from $1.7 \pm 0.18$ to $3.9 \pm 0.56(p<0.05)$ in the IGT group, being significantly higher in IGT than in NGT $(p<0.05)$.

Indices of beta cell function during i.v. glucose The beta cell glucose sensitivity to i.v. glucose was similar in the two groups before dexamethasone, and increased by approximately $100 \%$ in NGT and $40 \%$ in IGT after dexamethasone $(p<0.05$; Table 3$)$. $\mathrm{D}_{\mathrm{I}(\text { Glucose sensitivity })}$ to i.v. glucose did not differ between the groups before dexamethasone. After treatment $\mathrm{D}_{\mathrm{I}(\mathrm{Glucose}}$ sensitivity) decreased significantly in both groups, and was significantly more reduced in the IGT group compared with the NGT group ( $p<0.05$; Table 3 ).

The beta cell index increased numerically in both groups after dexamethasone, but only significantly in the NGT group. It was similar in the two groups before but significantly smaller in IGT compared with NGT after dexamethasone (Table 3). $\mathrm{D}_{\mathrm{I} \text { (Beta cell index) }}$ did not differ between the groups before dexamethasone. $\mathrm{D}_{\mathrm{I}(\text { Beta cell index) }}$ decreased significantly in IGT after dexamethasone and was significantly smaller compared with NGT $(p<0.05$; Table 3$)$.

Indices of beta cell function during OGTT The beta cell glucose sensitivity during OGTT (Table 3) illustrates the potentiating effect of the incretin hormones when compared with beta cell glucose sensitivity during i.v. glucose. The beta cell glucose sensitivity during OGTT did not differ before dexamethasone. After treatment, beta cell glucose sensitivity increased significantly in the NGT group, while the absence of an increase in the IGT group is in accordance with the severely reduced incretin effect (Table 3). The $\mathrm{D}_{\mathrm{I}(\text { Glucose sensitivity) }}$ during OGTT was significantly lower in the IGT group before and decreased significantly in both groups after dexamethasone, and was significantly lower in the IGT group compared with the NGT group after dexamethasone (Table 3).

The beta cell index was similar during OGTT in the two groups before, but significantly lower in IGT compared with NGT after dexamethasone (Table 3). The $\mathrm{D}_{\text {I(Beta cell index) }}$ during OGTT did not differ between the groups before treatment. After treatment, a significant reduction was observed in both groups, with a significantly lower $\mathrm{D}_{\text {I(Beta cell index) }}$ in the IGT group compared with the NGT group (Table 3). 
Table 3 Incremental beta cell secretory responses (insulin, Cpeptide, ISR) to oral glucose and i.v. isoglycaemic glucose infusion, incretin effects in the NGT and IGT groups before and after dexamethasone, and indices of beta cell function
The iAUCs were calculated using the total duration of the tests from 0 to $240 \mathrm{~min}$

*Significant differences between OGTT and i.v. glucose infusion within groups $(p<0.05)$

${ }^{\dagger}$ Significant differences within groups after compared with before treatment $(p<0.05)$

${ }^{\ddagger}$ Significant difference between groups $(p<0.05)$

\begin{tabular}{|c|c|c|c|c|}
\hline \multirow[t]{2}{*}{ Group } & \multicolumn{2}{|c|}{ Before dexamethasone } & \multicolumn{2}{|c|}{ After dexamethasone } \\
\hline & NGT & IGT & NGT & IGT \\
\hline$n$ (women/men) & $4 / 6$ & $5 / 6$ & $4 / 6$ & $5 / 6$ \\
\hline \multicolumn{5}{|l|}{ Insulin (nmol/1× min) } \\
\hline OGTT & $27 \pm 3.5^{*}$ & $33 \pm 3.6^{*}$ & $86 \pm 17.6^{*, \dagger}$ & $80 \pm 10.0^{*, \dagger}$ \\
\hline i.v. glucose infusion & $8.5 \pm 1.9$ & $11 \pm 2.1$ & $35 \pm 7.6 \dagger$ & $51 \pm 8.0 \dagger$ \\
\hline Mixed meal & $30 \pm 6.8$ & $23 \pm 2.6$ & $55 \pm 8.8^{\dagger}$ & $60 \pm 7.2 \dagger$ \\
\hline \multicolumn{5}{|l|}{ C-peptide $(\mathrm{nmol} / 1 \times \min )$} \\
\hline OGTT & $264 \pm 22^{*}$ & $288 \pm 25^{*}$ & $533 \pm 66^{*}, \dagger$ & $456 \pm 49^{*, \dagger}$ \\
\hline i.v. glucose infusion & $119 \pm 18$ & $146 \pm 15$ & $286 \pm 29 \dagger$ & $366 \pm 28 \dagger$ \\
\hline Mixed meal & $248 \pm 29$ & $198 \pm 14$ & $393 \pm 41^{\dagger}$ & $342 \pm 36 \dagger$ \\
\hline \multicolumn{5}{|l|}{ ISR (nmol kg-1 $\min ^{-1}$ ) } \\
\hline OGTT & $1.0 \pm 0.09^{*}$ & $1.0 \pm 0.1^{*}$ & $2.0 \pm 0.3^{*, \dagger}$ & $1.7 \pm 0.2^{*, \dagger}$ \\
\hline i.v. glucose infusion & $0.4 \pm 0.06$ & $0.5 \pm 0.07$ & $1.0 \pm 0.1^{\dagger}$ & $1.3 \pm 0.1^{\dagger}$ \\
\hline Mixed meal & $1.0 \pm 0.1$ & $0.8 \pm 0.08$ & $1.5 \pm 0.1^{\dagger}$ & $1.2 \pm 0.2^{\dagger}$ \\
\hline \multicolumn{5}{|l|}{ Incretin effect (\%) } \\
\hline Insulin & $71 \pm 3.2$ & $67 \pm 4.6$ & $58 \pm 5.2^{\dagger,+}$ & $32 \pm 8.8^{\dagger, *}$ \\
\hline C-peptide & $56 \pm 4.0$ & $49 \pm 3.8$ & $40 \pm 7.9^{\dagger, 末}$ & $13 \pm 8.0^{\dagger, *}$ \\
\hline ISR & $55 \pm 4.1$ & $49 \pm 4.0$ & $41 \pm 7.1^{\ddagger}$ & $13 \pm 7.7^{\dagger, *}$ \\
\hline \multicolumn{5}{|c|}{ Beta cell glucose sensitivity $\left(\mathrm{nmol} \mathrm{kg}{ }^{-1} \min ^{-1} \mathrm{mmol} / 1^{-1}\right)$} \\
\hline OGTT & $2.8 \pm 0.31^{*}$ & $1.9 \pm 0.14^{*}$ & $3.4 \pm 0.42^{*}, \dagger$, & $1.9 \pm 0.36^{*}$ \\
\hline i.v. glucose infusion & $1.0 \pm 0.12$ & $1.0 \pm 0.07$ & $2.1 \pm 0.20 \dagger$ & $1.4 \pm 0.23 \dagger$ \\
\hline Mixed meal & $4.2 \pm 0.61$ & $2.8 \pm 0.27$ & $6.2 \pm 0.98$ & $3.7 \pm 0.47$ \\
\hline \multicolumn{5}{|c|}{$\mathrm{D}_{\mathrm{I}}\left(\right.$ Glucose sensitivity) $\left(\mathrm{nmol} \mathrm{kg}{ }^{-1} \min ^{-1} \mathrm{mmol} / \mathrm{I}^{-1}\right)$} \\
\hline OGTT & $23 \pm 3.7^{*}$ & $14 \pm 2.3^{*}$, & $12 \pm 2.2^{*, \dagger, *}$ & $5.6 \pm 0.76^{\dagger+}$ \\
\hline i.v. glucose infusion & $8.8 \pm 0.94$ & $6.7 \pm 0.92$ & $7.3 \pm 1.2^{\ddagger}$ & $4.2 \pm 0.47^{\dagger+}$ \\
\hline Mixed meal & $34 \pm 6.8$ & $20 \pm 4.0$ & $21 \pm 4.1^{*}$ & $11 \pm 1.2^{\dagger, *}$ \\
\hline \multicolumn{5}{|c|}{ Beta cell index $\left(\mathrm{nmol} \mathrm{kg}{ }^{-1} \mathrm{~min}^{-1} \mathrm{mmol} / \mathrm{l}^{-1}\right)$} \\
\hline OGTT & $4.5 \pm 0.67^{*}$ & $4.2 \pm 0.88^{*}$ & $8.8 \pm 1.4^{*, \dagger, *}$ & $3.4 \pm 0.60^{*}$ \\
\hline i.v. glucose infusion & $1.7 \pm 0.21$ & $1.9 \pm 0.27$ & $3.9 \pm 0.48^{\dagger, \dagger}$ & $2.6 \pm 0.3^{\ddagger}$ \\
\hline Mixed meal & $4.9 \pm 0.64$ & $5.2 \pm 0.53$ & $8.8 \pm 1.1^{\dagger}$ & $6.7 \pm 1.3$ \\
\hline \multicolumn{5}{|c|}{$\mathrm{D}_{\mathrm{I}(\text { Beta cell index })}\left(\mathrm{nmol} \mathrm{kg}{ }^{-1} \mathrm{~min}^{-1} \mathrm{mmol} / \mathrm{l}^{-1}\right)$} \\
\hline OGTT & $37 \pm 6.4^{*}$ & $27 \pm 8.0^{*}$ & $29 \pm 6.1^{*, \dagger, *}$ & $8.4 \pm 1.4^{*}, \dagger,+$ \\
\hline i.v. glucose infusion & $14 \pm 1.6$ & $12 \pm 2.5$ & $14 \pm 2.9^{*}$ & $6.2 \pm 0.7^{\dagger, 末}$ \\
\hline Mixed meal & $41 \pm 8.5$ & $32 \pm 5.3$ & $30 \pm 5.1$ & $17 \pm 2.8^{\dagger, 末}$ \\
\hline
\end{tabular}

Indices of beta cell function during mixed meal During the mixed meal, the beta cell glucose sensitivity and beta cell index did not differ significantly between groups before and after dexamethasone (Table 3 ). The $\mathrm{D}_{\mathrm{I} \text { (Glucose sensitivity) was }}$ numerically reduced in both groups after dexamethasone but only significantly in the IGT group, and was significantly lower in IGT compared with NGT ( $p<0.05$, Table 3$)$. D I(Beta cell index) decreased significantly only in IGT after dexamethasone, and was significantly lower after treatment in IGT compared with NGT (Table 3 ). When comparing the mixed meal and OGTT, the $\mathrm{D}_{\mathrm{I} \text { (Glucose sensitivity) }}$ was greater during the mixed meal in both groups both before and after dexamethasone $(p<0.05$, Table 3$)$. $\mathrm{D}_{\mathrm{I}(\text { Beta cell index) }}$ was also numerically greater when comparing the OGTT and mixed meal, but this failed to reach statistical significance, except for IGT after dexamethasone (Table 3).

Glucagon Fasting plasma glucagon increased significantly in both groups after treatment (NGT, from $8.1 \pm 0.54$ to $12.3 \pm$ $1.04 \mathrm{pmol} / \mathrm{l}$; IGT, from $9.6 \pm 0.66$ to $14.0 \pm 0.91 \mathrm{pmol} / \mathrm{l})(p<$ 0.05 ) (Figs $2 \mathrm{i}-1$ and $4 \mathrm{i}-1$ ), with no difference between groups. The AUC and iAUC did not differ between groups during any test before treatment (Table 3). After dexamethasone, the iAUC decrement after OGTT and i.v. glucose increased in both NGT and IGT (Table 3). The suppression of glucagon was slightly but insignificantly delayed during the first $45 \mathrm{~min}$ 
during oral compared with i.v. glucose in the NGT group, while in the IGT group the glucagon suppression was significantly greater during i.v. glucose compared with OGTT ( $p<$ $0.05)$. This was mainly due to a significant $(p<0.05)$ delay in glucagon suppression during the first 120 min during OGTT (Fig. 2k-1). The AUC increased significantly in all tests except in the NGT group during OGTT, which probably represents a type II error. The AUC during the mixed meal increased significantly in both groups, with no significant differences between groups in any tests using AUC.

\section{Discussion}

In the current study, we confirm that the incretin effect is intact in healthy first-degree relatives of type 2 diabetes patients, amounting to approximately $70 \%$, as previously observed [34]. However, the incretin effect was reduced when insulin resistance increased, even while normal glucose tolerance was maintained. When our participants developed glucose intolerance in addition to insulin resistance, we observed a further, significant, decline in the incretin effect. As the increase in insulin resistance in the two groups was identical, our results suggest that insulin resistance and glucose intolerance contribute as separate factors to the reduced incretin effect in patients with type 2 diabetes. Even though our study design per se does not allow us to conclude that the reduced incretin effect observed is a consequence and not a cause of the declining glucose tolerance, previous studies $[11,35]$ from our group have addressed this question, and together the evidence supports the former.

The mechanistic explanation for the impaired incretin effect in our study does not involve a reduced secretion of the two incretin hormones GLP-1 and GIP (measured as total hormones to capture all changes in secretion, independent of possible variations in dipeptidyl peptidase-4 (DPP4) activity [36]) as neither GLP-1 nor GIP secretion decreased during OGTT after dexamethasone. Therefore, the present results indicate that the decline in the incretin effect is due to a loss of the insulinotropic properties of the two incretin hormones, which is most pronounced in the IGT group. A previous study in a population without genetic disposition to type 2 diabetes similarly found that steroid treatment did not change the overall secretion of GLP-1 but led to an increase in overall secretion of GIP and glucagon during a mixed meal [37].

Insulin resistance induced with 5 days of dexamethasone was based on previous studies [13], which, in agreement with the present study, showed that some individuals treated with dexamethasone developed IGT while the others remained NGT. On the three consecutive test days immediately after the 5 days of dexamethasone the fasting concentrations of glucose and insulin did not increase or decrease from day 1 to 3 , suggesting that a steady state, with regard to insulin resistance, had been reached.

In addition to reduced insulin-mediated peripheral glucose disposal [38, 39], glucocorticoids are also known to reduce oxidative and non-oxidative pathways of glucose disposal [38], reduce muscle glycogen synthase activity [40], and to induce hepatic insulin resistance [39]. As such, the insulin resistance induced by glucocorticoids resembles the insulin resistance seen in type 2 diabetes. The NGT group did show a small increase in FPG and $\mathrm{AUC}_{\text {Glucose }}$ after dexamethasone, but this increase was small indicating that the beta cell could compensate adequately for the increasing insulin resistance.

As beta cell function is a determinant of normal or abnormal glucose tolerance, we calculated indices of beta cell function. The proinsulin/C-peptide ratio is a sensitive index of beta cell dysfunction, and has been reported to predict the risk of type 2 diabetes in individuals with NGT [41], increasing progressively as beta cell function decreases and glycaemia increases [42]. The proinsulin/C-peptide ratio increased after dexamethasone in both groups, but more marked in the IGT group. The increase in the ratio may reflect the increased demand for insulin, forcing the beta cell to secrete immature granules with a high content of proinsulin, as previous reported by Kahn et al [43].

The insulin response to i.v. glucose is impaired early in the development of type 2 diabetes, and is one of the factors determining the progression from normal to abnormal glucose tolerance [44]. Beta cell glucose sensitivity is an integrated measure of glucose-induced insulin secretion over hours, and was significantly impaired in the IGT group, with an approximately $40 \%$ decrease after dexamethasone when corrected for insulin resistance by calculation of the $\mathrm{D}_{\mathrm{I}(\text { Glucose sensitivity)} \text {; the decrease was numerically }}$ lower in the NGT group, and failed to reach statistical significance. The third index we calculated, $\mathrm{D}_{\mathrm{I}(\text { Beta cell index), }}$, decreased significantly in the IGT group. Taken together, the results indicate that the reduced incretin effect is an early phenomenon in the development of type 2 diabetes, which is, in part, due to a general beta cell dysfunction. It was observed in people with preserved NGT, and in whom the proinsulin/C-peptide ratio was significantly increased, and the $\mathrm{D}_{\mathrm{I}(\text { Beta cell index) }}$ and $\mathrm{D}_{\mathrm{I}(\text { Glucose sensitivity) }}$ were not significantly reduced. Along with the progressive impairment in the incretin effect in the group developing IGT, parallel statistically significant reductions in $\mathrm{D}_{\mathrm{I}(\mathrm{Glucose} \text { sensitivity) }}$ and $\mathrm{D}_{\mathrm{I}(\text { Beta cell index) }}$ were observed, indicating a more severe global beta cell dysfunction.

The beta cell glucose sensitivity to oral glucose was greater in both groups compared with i.v. glucose before dexamethasone, and in the NGT group after dexamethasone, in accordance with the potentiation of insulin secretion by the incretin hormones. In the participants with IGT, the beta 
cell glucose sensitivity did not differ significantly during the i.v. glucose and OGTT, in accordance with the severe impairment of the incretin effect in this group after dexamethasone. Interestingly, during the mixed meal, where insulin secretion is stimulated not only by the incretin hormones but also by non-glucose substrates and neurotransmitters, the beta cell glucose sensitivity and the beta cell index were numerically greater compared with oral glucose, except for the beta cell index in NGT after dexamethasone, which was similar. This indicates a greater potentiation of glucoseinduced insulin release by mixed-meal stimulation than by OGTT, where primarily the incretin hormones and glucose stimulate insulin release.

Recently, it has been argued [45] that the maximal secretory capacity of the beta cells is reached during the IVGTT of isoglycaemic challenges for the study of incretin effect in type 2 diabetes, meaning that the incretin hormones cannot further increase insulin secretion on oral stimulation, which could explain the apparent loss of the incretin effect. However, in our participants with NGT, this is unlikely to be the cause of the reduced incretin effect, particularly as the beta cell response to the mixed meal was significantly greater than to i.v. glucose after glucocorticoid treatment. In addition, other studies showed that supraphysiological concentrations of GLP-1 dramatically increased glucose-induced insulin secretion in type 2 diabetes $[10,46]$.

Regarding glucagon, we found that the increase in insulin resistance was associated with an inappropriate large increase in glucagon secretion. This is of interest because an increase in glucagon secretion is an important diabetogenic factor in type 2 diabetes. Alpha cell dysfunction must therefore be included among the diabetogenic effects of glucocorticoids. Furthermore, the increase in both groups point to alpha cell dysfunction as a very early sign in diabetes development. A delayed glucagon suppression during OGTT, as seen here in the IGT group after dexamethasone, has also been observed in type 2 diabetes [47].

Acknowledgements We acknowledge the excellent technical assistance of L. Spurr, N. Kjeldsen, S. Polmann and S. Pilgaard.

Funding This study was supported by a grant from the Novo Nordisk Foundation.

Contribution statement DHJ analysed and collected the data, drafted the manuscript and approved the final version. All other authors have made significant contributions to the conception, design, or analysis and interpretation of presented data as well as in drafting the article or revising it critically for important intellectual content and gave their approval for the final version.

Duality of interest The authors declare that there is no duality of interest associated with this manuscript.

\section{References}

1. Expert Committee on the Diagnosis and Classification of Diabetes Mellitus (2003) Report of the expert committee on the diagnosis and classification of diabetes mellitus. Diabetes Care 26(Suppl 1): S5-S20

2. Holst JJ (2007) The physiology of glucagon-like peptide 1. Physiol Rev 87:1409-1439

3. Dube PE, Brubaker PL (2004) Nutrient, neural and endocrine control of glucagon-like peptide secretion. Horm Metab Res $36: 755-760$

4. Holst JJ, Deacon CF, Vilsboll T, Krarup T, Madsbad S (2008) Glucagon-like peptide-1, glucose homeostasis and diabetes. Trends Mol Med 14:161-168

5. Nauck M, Stöckmann F, Ebert R, Creutzfeldt W (1986) Reduced incretin effect in Type 2 (non-insulin-dependent) diabetes. Diabetologia 29:46-52

6. Perley MJ, Kipnis DM (1967) Plasma insulin responses to oral and intravenous glucose: studies in normal and diabetic subjects. J Clin Invest 46:1954-1962

7. Muscelli E, Mari A, Natali A et al (2006) Impact of incretin hormones on beta-cell function in subjects with normal or impaired glucose tolerance. Am J Physiol Endocrinol Metab 291:E1144E1150

8. Muscelli E, Mari A, Casolaro A et al (2008) Separate impact of obesity and glucose tolerance on the incretin effect in normal subjects and type 2 diabetic patients. Diabetes 57:1340-1348

9. Kjems LL, Holst JJ, Volund A, Madsbad S (2003) The influence of GLP-1 on glucose-stimulated insulin secretion: effects on $\beta$ cell sensitivity in type 2 and nondiabetic subjects. Diabetes 52:380-386

10. Vilsboll T, Krarup T, Madsbad S, Holst JJ (2002) Defective amplification of the late phase insulin response to glucose by GIP in obese Type II diabetic patients. Diabetologia 45:1111-1119

11. Knop FK, Vilsboll T, Hojberg PV et al (2007) Reduced incretin effect in type 2 diabetes: cause or consequence of the diabetic state? Diabetes 56:1951-1959

12. Beck-Nielsen H, Groop LC (1994) Metabolic and genetic characterization of prediabetic states. Sequence of events leading to noninsulin-dependent diabetes mellitus. J Clin Invest 94:1714-1721

13. Henriksen JE, Alford F, Ward GM, Beck-Nielsen H (1997) Risk and mechanism of dexamethasone-induced deterioration of glucose tolerance in non-diabetic first-degree relatives of NIDDM patients. Diabetologia 40:1439-1448

14. Nauck M, Homberger E, Siegel E et al (1986) Incretin effects of increasing glucose loads in man calculated from venous insulin and C-peptide responses. J Clin Endocrinol Metab 63:492-498

15. Porte D Jr (1991) Banting lecture 1990. Beta-cells in type II diabetes mellitus. Diabetes 40:166-180

16. Cohen RM, Nathan DM, Clements RS Jr (1992) Hyperproinsulinemia in type II diabetes. Diabetes Care 15:723-724

17. Kahn SE, Prigeon RL, McCulloch DK et al (1993) Quantification of the relationship between insulin sensitivity and beta-cell function in human subjects. Evidence for a hyperbolic function. Diabetes 42:1663-1672

18. Bagdade JD, Porte D Jr, Brunzell JD, Bierman EL (1974) Basal and stimulated hyperinsulinism: reversible metabolic sequelae of obesity. J Lab Clin Med 83:563-569

19. Kahn SE (2003) The relative contributions of insulin resistance and beta-cell dysfunction to the pathophysiology of type 2 diabetes. Diabetologia 46:3-19

20. Bergman RN, Ader M, Huecking K, van Citters G (2002) Accurate assessment of beta-cell function - The hyperbolic correction. Diabetes 51:S212-S220

21. Alberti K, Zimmet PZ, Consultation WHO (1998) Definition, diagnosis and classification of diabetes mellitus and its complications part 1: 
Diagnosis and classification of diabetes mellitus - Provisional report of a WHO consultation. Diabetic Med 15:539-553

22. World Health Organisation (2006) Definition and diagnosis of diabetes mellitus and intermediate hyperglycemia: report of a WHO/IDF consultation. WHO, Geneva

23. Nauck MA, Liess H, Siegel EG, Niedmann PD, Creutzfeldt W (1992) Critical evaluation of the 'heated-hand-technique' for obtaining 'arterialized' venous blood: incomplete arterialization and alterations in glucagon responses. Clin Physiol 12:537-552

24. Orskov C, Rabenhoj L, Wettergren A, Kofod H, Holst JJ (1994) Tissue and plasma concentrations of amidated and glycine-extended glucagon-like peptide I in humans. Diabetes 43:535-539

25. Krarup T, Holst JJ (1984) The heterogeneity of gastric inhibitory polypeptide in porcine and human gastrointestinal mucosa evaluated with five different antisera. Regul Pept 9:35-46

26. Krarup T, Madsbad S, Moody AJ et al (1983) Diminished immunoreactive gastric inhibitory polypeptide response to a meal in newly diagnosed type I (insulin-dependent) diabetics. J Clin Endocrinol Metab 56:1306-1312

27. Orskov C, Jeppesen J, Madsbad S, Holst JJ (1991) Proglucagon products in plasma of noninsulin-dependent diabetics and nondiabetic controls in the fasting state and after oral glucose and intravenous arginine. J Clin Invest 87:415-423

28. Baldissera FG, Holst JJ (1984) Glucagon-related peptides in the human gastrointestinal mucosa. Diabetologia 26:223-228

29. Holst JJ, Pedersen JH, Baldissera F, Stadil F (1983) Circulating glucagon after total pancreatectomy in man. Diabetologia 25:396399

30. Kjems LL, Roder ME, Dinesen B, Hartling SG, Jorgensen PN, Binder C (1993) Highly sensitive enzyme immunoassay of proinsulin immunoreactivity with use of two monoclonal antibodies. Clin Chem 39:2146-2150

31. Kjems LL, Christiansen E, Volund A, Bergman RN, Madsbad S (2000) Validation of methods for measurement of insulin secretion in humans in vivo. Diabetes 49:580-588

32. Matsuda M, DeFronzo RA (1999) Insulin sensitivity indices obtained from oral glucose tolerance testing: comparison with the euglycemic insulin clamp. Diabetes Care 22:1462-1470

33. Retnakaran R, Shen S, Hanley AJ, Vuksan V, Hamilton JK, Zinman B (2008) Hyperbolic relationship between insulin secretion and sensitivity on oral glucose tolerance test. Obesity 16:1901-1907

34. Nauck MA, El-Ouaghlidi A, Gabrys B et al (2004) Secretion of incretin hormones (GIP and GLP-1) and incretin effect after oral glucose in first-degree relatives of patients with type 2 diabetes. Regul Pept 122:209-217
35. Højberg P, Zander M, Vilsbøll T et al (2008) Near normalisation of blood glucose improves the potentiating effect of GLP-1 on glucose-induced insulin secretion in patients with type 2 diabetes. Diabetologia 51:632-640

36. Deacon CF, Holst JJ (2009) Immunoassays for the incretin hormones GIP and GLP-1. Best Pract Res Clin Endocrinol Metab 23:425-432

37. Hansen KB, Vilsboll T, Bagger JI, Holst JJ, Knop FK (2011) Increased postprandial GIP and glucagon responses, but unaltered GLP-1 response after intervention with steroid hormone, relative physical inactivity, and high-calorie diet in healthy subjects. J Clin Endocrinol Metab 96:447-453

38. Tappy L, Randin D, Vollenweider P et al (1994) Mechanisms of dexamethasone-induced insulin resistance in healthy humans. J Clin Endocrinol Metab 79:1063-1069

39. McMahon M, Gerich J, Rizza R (1988) Effects of glucocorticoids on carbohydrate metabolism. Diabetes Metab Rev 4:17-30

40. Coderre L, Srivastava AK, Chiasson JL (1992) Effect of hypercorticism on regulation of skeletal muscle glycogen metabolism by epinephrine. Am J Physiol 262:E434-E439

41. Kahn SE, Leonetti DL, Prigeon RL, Boyko EJ, Bergstrom RW, Fujimoto WY (1995) Proinsulin as a marker for the development of NIDDM in Japanese-American men. Diabetes 44:173-179

42. Roder ME, Porte D Jr, Schwartz RS, Kahn SE (1998) Disproportionately elevated proinsulin levels reflect the degree of impaired B cell secretory capacity in patients with noninsulin-dependent diabetes mellitus. J Clin Endocrinol Metab 83:604-608

43. Kahn SE, Horber FF, Prigeon RL, Haymond MW, Porte D (1993) Effect of glucocorticoid and growth hormone treatment on proinsulin levels in humans. Diabetes 42:1082-1085

44. Ferrannini E, Gastaldelli A, Miyazaki Y, Matsuda M, Mari A, DeFronzo RA (2005) beta-Cell function in subjects spanning the range from normal glucose tolerance to overt diabetes: a new analysis. J Clin Endocrinol Metab 90:493-500

45. Meier JJ, Nauck MA (2010) Is the diminished incretin effect in type 2 diabetes just an epi-phenomenon of impaired $\beta$-cell function? Diabetes 59:1117-1125

46. Vilsboll T, Toft-Nielsen MB, Krarup T, Madsbad S, Dinesen B, Holst JJ (2000) Evaluation of beta-cell secretory capacity using glucagon-like peptide 1. Diabetes Care 23:807-812

47. Knop FK, Vilsboll T, Madsbad S, Holst JJ, Krarup T (2007) Inappropriate suppression of glucagon during OGTT but not during isoglycaemic i.v. glucose infusion contributes to the reduced incretin effect in type 2 diabetes mellitus. Diabetologia 50:797805 